\title{
CHIARITÉ
}

\section{Subjective hearing ability, physical and mental comorbidities in individuals with bothersome tinnitus in a Swedish population sample}

Laura Basso, Benjamin Boecking, Petra Brueggemann, Nancy L. Pedersen, Barbara Canlon, Christopher R. Cederroth, Birgit Mazurek

\section{Document type}

Book Chapter

This version is available at

https://doi.org/10.17169/refubium-29568

\section{Citation details}

Basso L, Boecking B, Brueggemann P, Pedersen NL, Canlon B, Cederroth CR, et al. Subjective hearing ability, physical and mental comorbidities in individuals with bothersome tinnitus in a Swedish population sample. Progress in Brain Research. [Online] Elsevier; 2021. p. 51-78. DOI: 10.1016/bs.pbr.2020.10.001

\section{Terms of use}

All rights reserved. This document is intended solely for personal, non-commercial use. 


\title{
Subjective hearing ability, physical and mental comorbidities in individuals with bothersome tinnitus in a Swedish population sample
}

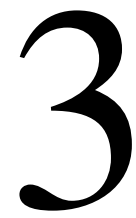

\author{
Laura Basso ${ }^{\mathrm{a}}$, Benjamin Boecking ${ }^{\mathrm{a}}$, Petra Brueggemann ${ }^{\mathrm{a}}$, Nancy L. Pedersen ${ }^{\mathrm{b}}$, \\ Barbara Canlon ${ }^{\mathrm{c}}$, Christopher R. Cederroth ${ }^{\mathrm{c}, \mathrm{d}, \mathrm{e}}$, and Birgit Mazurek ${ }^{\mathrm{a}, *}$ \\ ${ }^{a}$ Tinnitus Center, Charité-Universitätsmedizin Berlin, Berlin, Germany \\ ${ }^{\mathrm{b}}$ Department of Medical Epidemiology and Biostatistics, Karolinska Institutet, Stockholm, Sweden \\ ${ }^{\mathrm{c}}$ Laboratory of Experimental Audiology, Department of Physiology and Pharmacology, \\ Karolinska Institutet, Stockholm, Sweden \\ ${ }^{\mathrm{d}}$ National Institute for Health Research (NIHR) Nottingham Biomedical Research Centre, \\ Nottingham University Hospitals NHS Trust, Nottingham, United Kingdom \\ ${ }^{\mathrm{e}}$ Hearing Sciences, Division of Clinical Neuroscience, School of Medicine, University of \\ Nottingham, Nottingham, United Kingdom \\ *Corresponding author: Tel.: +49-30-450-555-061, e-mail address: birgit.mazurek@charite.de
}

\section{Abstract}

Objective: This study investigates associations of subjective hearing ability, physical comorbidities, and mental comorbidities with bothersome (vs. non-bothersome) tinnitus and mediating effects between these influences.

Methods: The Swedish LifeGene cohort was used to sample cross-sectional survey data (collected 2009-2016) of 7615 participants with tinnitus, 697 (9.2\%) of whom rated their tinnitus as bothersome. Associations between bothersome tinnitus and subjective hearing ability, physical and mental comorbidities were investigated by separate age- and gender-adjusted multiple logistic regression models. Interrelationships between these associations were investigated by logistic mediation models.

Results: Compared to non-bothersome tinnitus, bothersome tinnitus was associated with higher age, reduced subjective hearing ability, hearing-related difficulties in social situations, cardiovascular disease, chronic shoulder pain, thyroid disease, Ménière's disease, depression, anxiety 
syndrome, and social anxiety. Subjective hearing impairment or hearing-related difficulties mediated $13-36 \%$ of the effects of mental comorbidities on bothersome tinnitus. Depression or anxiety syndrome mediated 5-8\% of most relationships between physical comorbidities and bothersome tinnitus. Depression, anxiety syndrome, or social anxiety mediated 2-4\% of the effects of subjective hearing impairment or hearing-related difficulties on bothersome tinnitus.

Conclusion: Psychological factors, subjective hearing impairment, and hearing-related difficulties in social situations play key roles in predicting bothersome (vs. non-bothersome) tinnitus in a large population sample. Psychological factors contribute to explaining the impact of physical comorbidities and hearing-related effects on bothersome tinnitus. This highlights their transdiagnostic importance for aggravating varied physical symptom clusters. Interventions to improve or prevent high tinnitus burden should be interdisciplinary/multimodal and target auditory, physical, and psychological factors.

\section{Keywords}

Bothersome tinnitus, Physical comorbidity, Mental comorbidity, Hearing ability, Mediation analysis

\section{Introduction}

Tinnitus, commonly defined as the sensation of sound without a corresponding external acoustic source, can lead to considerable distress (Tyler and Baker, 1983) and an increased risk for suicide attempts (Lugo et al., 2019; Seo et al., 2016). Most individuals who are affected by tinnitus, however, report not to be bothered by it; e.g., in a study by Kim et al. (2015) in the South Korean population, $69.2 \%$ of subjects with tinnitus reported no tinnitus-related annoyance, $27.9 \%$ slight annoyance, and 3.0\% severe annoyance. Regarding factors that distinguish between low levels of tinnitusrelated distress (non-bothersome tinnitus) and high levels of tinnitus-related distress (bothersome tinnitus), influences of psychological factors such as maladaptive coping styles (Beukes et al., 2018; Budd and Pugh, 1996), cognitive factors (Caldirola et al., 2016; Lee et al., 2004; Weise et al., 2013), and stress (Baigi et al., 2011; Ciminelli et al., 2018; Kim et al., 2015) have been identified. Moreover, rates of mental comorbidities are high among individuals with tinnitus and they seem to correlate with tinnitus severity (Pinto et al., 2014). Anxiety disorders (45\% lifetime prevalence; Pattyn et al., 2016) and depressive disorders (33\% median prevalence; Salazar et al., 2019) are most predominant. It is also known that certain physical conditions are associated with tinnitus; see Table 1 for an overview of physical and mental comorbidities with associations to tinnitus (and potentially bothersome tinnitus) which are included in the present study.

The presence of physical symptoms can lead to psychosocial distress, and previous studies report associations between somatic complaints and tinnitus-related distress (Brueggemann et al., 2016; Hoekstra et al., 2014; Sahin et al., 2016; Stobik et al., 2005). Furthermore, there is strong evidence from research on chronic pain disorders that psychological processes can play a major role in the perception and chronification of physical symptoms (Borsook et al., 2018; Nees and Becker, 2018), and not surprisingly, tinnitus and chronic pain share many neurological similarities (Rauschecker et al., 2015). 
Table 1 Selected physical and mental comorbidities with associations to tinnitus.

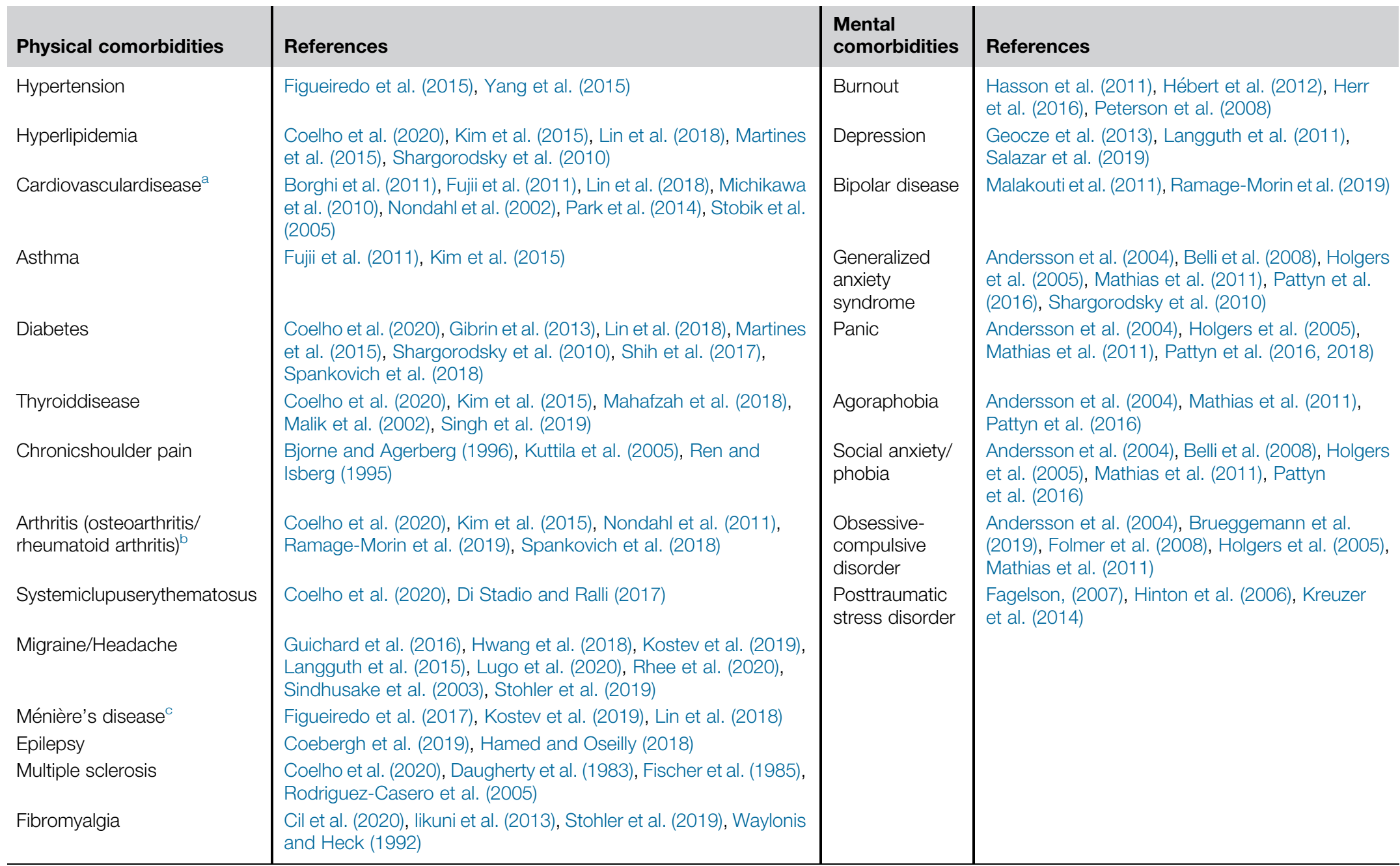

aln the present study, angina, myocardial infarction, and cardiac arrhythmia were grouped as cardiovascular diseases.

$\mathrm{b} / \mathrm{n}$ the present study, osteoarthritis and rheumatoid arthritis were differentiated, which has not been done consistently in the literature.

'Ménière's disease is not a comorbidity but was included as tinnitus can be a symptom of Ménière's disease. 
Bothersome tinnitus is likely to be influenced by auditory and other physical factors as well as psychological factors. Previous studies that have investigated factors which can influence tinnitus-related distress have either looked at single factors (Ciminelli et al., 2018; Sahin et al., 2016) or multiple factors, e.g., in multivariate regression approaches (Brueggemann et al., 2016; Hoekstra et al., 2014; Kim et al., 2015), but how influences of different factors might affect each other has rarely been explored.

The current study aims not only to investigate the contributions of subjective hearing ability, physical symptoms, and mental symptoms in the prediction of bothersome (vs. non-bothersome) tinnitus in a large Swedish population sample, but also possible interrelationships between these factors by using mediation analysis. Mediation analysis is a method to assess whether the relationship between an independent variable (e.g., migraine) and a dependent variable (e.g., bothersome tinnitus) is mediated, i.e., fully or partly explained by another variable (e.g., depression). Any variable that is related to the dependent and affected by the independent variable can be a potential mediator. In mediation analysis, it is assessed via three regression equations whether the relationship between the independent and the dependent variable changes when the mediator is controlled: if the relationship is reduced, the mediator partially accounts for the relationship; if the relationship is no longer present, the mediator fully accounts for it (Baron and Kenny, 1986). For example, Probst et al. (2016) found that the relationship between tinnitus loudness and tinnitus distress is partially mediated by stress level and emotional state.

The main objective of this study is to identify physical and mental comorbidities that are related to bothersome tinnitus (compared with non-bothersome tinnitus) and to investigate mediating effects by mental comorbidities. In addition, we also include subjective hearing ability in our analyses, as hearing impairment is a well-known risk factor for tinnitus (Henry et al., 2005; Shore et al., 2016) which might potentially mediate the effects of certain comorbidities on bothersome tinnitus. On the other hand, the influence of subjective hearing ability might also be mediated by the presence of mental comorbidities. Moreover, since the risk of tinnitus seems to increase with age, and conflicting findings have been made regarding tinnitus severity and gender (McCormack et al., 2016), we include these factors as covariates in our analyses. We hypothesize that the presence of mental comorbidities is strongly linked to bothersome tinnitus and partly explains the effects of physical comorbidities and subjective hearing impairment on bothersome tinnitus.

\section{Method}

\subsection{Study design and sample}

This study used cross-sectional survey data from the LifeGene cohort, a random sample from the Swedish general population (Almqvist et al., 2011; LifeGene, 2017). Recruitment of participants for LifeGene took place via invitation letters 
to randomly selected households (subjects aged 18-50 years), spontaneous online registration (for subjects aged $\geq 18$ years), or invitation by other participants (with the possibility for parents to invite their children; Almqvist et al., 2011; LifeGene, 2017). Other than age (invitation letters) and living in Sweden, no exclusion criteria were applied.

For this study, retrospective data of the LifeGene baseline survey (collected between 2009 and 2016) were used, which is a web-based epidemiological survey spanning different health-related themes (LifeGene, 2017). Of the $N=31,926$ participants who completed the survey, participants without tinnitus were excluded, leading to the final sample of $N=7615$ (23.9\%) of participants who reported to have tinnitus ("Is there a constant ringing in the ears or do you have any other bothersome sound in the ears [tinnitus]?"). The dependent variable for all analyses was the rating of the tinnitus as bothersome $(N=697 ; 9.2 \%)$ or non-bothersome $(N=6918 ; 90.8 \%)$. The same sample was used in Basso et al. (2020). The onset of the tinnitus and the percentage of study participants in clinical care due to their tinnitus are not known from the data.

On average, participants were 35.80 years old ( $S D=12.44$, range: $11-84$ years), and $56.5 \%(N=4301)$ were female. Forty-three participants $(0.6 \%)$ were younger than 18 years. Sample characteristics regarding marital status, education level, and employment status can be found in Table 2. Informed consent was obtained from all participants (for participants $<18$ years, consent was provided by the parents). In addition, the local ethics committee "Regionala etikprövningsnämnden" in Stockholm approved the project (2015/2129-31/1).

\subsection{Variables}

The LifeGene survey consists of various modules (LifeGene, 2017). All data used in this study were taken from the medical history module of the LifeGene survey (self-reported data).

\subsubsection{Outcome variable}

All participants who gave affirmative responses to the survey question on tinnitus ("Is there a constant ringing in the ears or do you have any other bothersome sound in the ears [tinnitus]?") were included in the study. Response options distinguished between "sometimes, but the sound doesn't bother me" and "all the time, the sound is very bothersome" which were classified as non-bothersome tinnitus and bothersome tinnitus, respectively.

\subsubsection{Predictors}

Predictors included physical and mental comorbidities and subjective hearing (subjective hearing ability and hearing-related difficulties in social situations). Physical and mental comorbidities were assessed by the question: "Which of the following diseases do you currently have or have you had?". All comorbidities included in this study can be found in Table 1. Angina, myocardial infarction, and cardiac arrhythmia 
Table 2 Sample characteristics: marital status, education level, and employment status.

\begin{tabular}{l|l|l} 
Variable & Percentage (\%) & N \\
Marital status & & 7381 \\
Cohabiting & 33.4 & 2544 \\
Married & 25.0 & 1904 \\
Single & 24.0 & 1824 \\
Living apart & 9.5 & 722 \\
Separated/divorced & 4.7 & 359 \\
Widowed & 0.3 & 25 \\
Same-sex marriage & 0.04 & 3 \\
Education level & & 7438 \\
University & 61.7 & 4696 \\
Secondary school & 24.9 & 1896 \\
Primary school (9years) & 2.7 & 205 \\
Other & 8.4 & 641 \\
Employment status & & 6726 \\
Employed & 53.7 & 4090 \\
Student & 15.0 & 1140 \\
Running owned or part-owned company & 7.8 & 592 \\
Age pension & 3.5 & 264 \\
Unemployed & 3.0 & 225 \\
Parental leave (for 2 months or longer) & 2.2 & 165 \\
Sick leave (for 2 months or longer) & 0.8 & 63 \\
Early retirement due to illness/disability & 0.7 & 57 \\
On leave & 0.1 & 10 \\
Housewife/-man & 0.1 & 10 \\
Other & 1.4 & 110 \\
\hline
\end{tabular}

were combined into cardiovascular diseases. Ménière's disease was included even though it is not strictly a comorbidity of tinnitus, but a disease which tinnitus can be part of. Regarding arthritis, the survey differentiated between osteoarthritis and rheumatoid arthritis, which has not been done consistently in the literature. In total, 15 physical and 9 mental comorbidities were analyzed.

Subjective hearing ability ("How is your hearing?") could either be rated as "good," "somewhat reduced" or "very reduced," but for our analyses, the latter two categories were combined into "reduced hearing ability". For the assessment of hearing-related difficulties in social situations, we calculated a mean score across the following items: "Do you have difficulties hearing when speaking to one person in a silent room?", "Do you have difficulties hearing when speaking to multiple people at the same time?", "Do you have difficulties hearing when 
speaking to someone in city traffic?", "Do you have difficulties hearing where different sounds come from, e.g., cars in traffic?" and "Do you have problems with your hearing and are therefore avoiding meeting people?" with the response options "yes, very difficult" (3), "sometimes, a little difficult" (2), and "no, not at all" (1). The mean score was then dichotomized into the presence or absence of hearing-related difficulties.

\subsection{Statistical analysis}

Statistical analyses comprised descriptive analyses, logistic regression models, and logistic mediation models and were computed using IBM SPSS Statistics (v. 25) for Windows 7. The significance level was set to $\alpha=0.05$.

\subsubsection{Descriptive analyses}

Pearson's Chi-Square tests (with continuity correction where applicable) and adjusted residuals $(A R s)$ were used to assess frequency differences between bothersome and non-bothersome tinnitus. Significant differences in category frequencies are present if $A R s \geq 1.96$ or $\leq-1.96$. Age was not normally distributed, but moderately right-skewed (skewness $=0.949, \mathrm{SE}=0.028$ ) and heavy-tailed (kurtosis $=0.494$, $\mathrm{SE}=0.056)$, Kolmogorov-Smirnov test: $\mathrm{D}(7615)=0.11, P<0.001$. Therefore, the non-parametric Mann-Whitney- $U$ test was used for its comparison between nonbothersome and bothersome tinnitus.

\subsubsection{Logistic regression models}

Associations with bothersome (vs. non-bothersome) tinnitus were identified using separate age- and gender-adjusted multiple logistic regression models for (1) subjective hearing (subjective hearing ability and hearing-related difficulties in social situations), (2) physical comorbidities (see Table 1), and (3) mental comorbidities (see Table 1), respectively. Odds ratios (ORs) with 95\%-CIs were calculated for all predictors, and Nagelkerke $R^{2}$ and effect size $f$ (Cohen, 1992, 1988) were used for model comparison. Regarding the assumptions of logistic regression, all variance inflation factor (VIF) values were $\leq 1.4$ (no multicollinearity among predictors), and the predictor age was linearly related to the log odds (Box-Tidwell approach). Concerning outliers, no cases with studentized residuals greater than 3 were present; cases with studentized residuals greater than 2 were not excluded $(N=267$ in model 1 ; $N=490$ in model 2; $N=490$ in model 3).

\subsubsection{Logistic mediation models}

Interrelationships between factors that significantly predicted bothersome (vs. nonbothersome) tinnitus in regression analyses were further analyzed in logistic mediation models, as described by Herr (2006), based on equations from Mackinnon and Dwyer (1993). Logistic mediation models analyzed: (A) if subjective hearing ability mediated the relationship between mental comorbidities and bothersome tinnitus; (B) if mental 


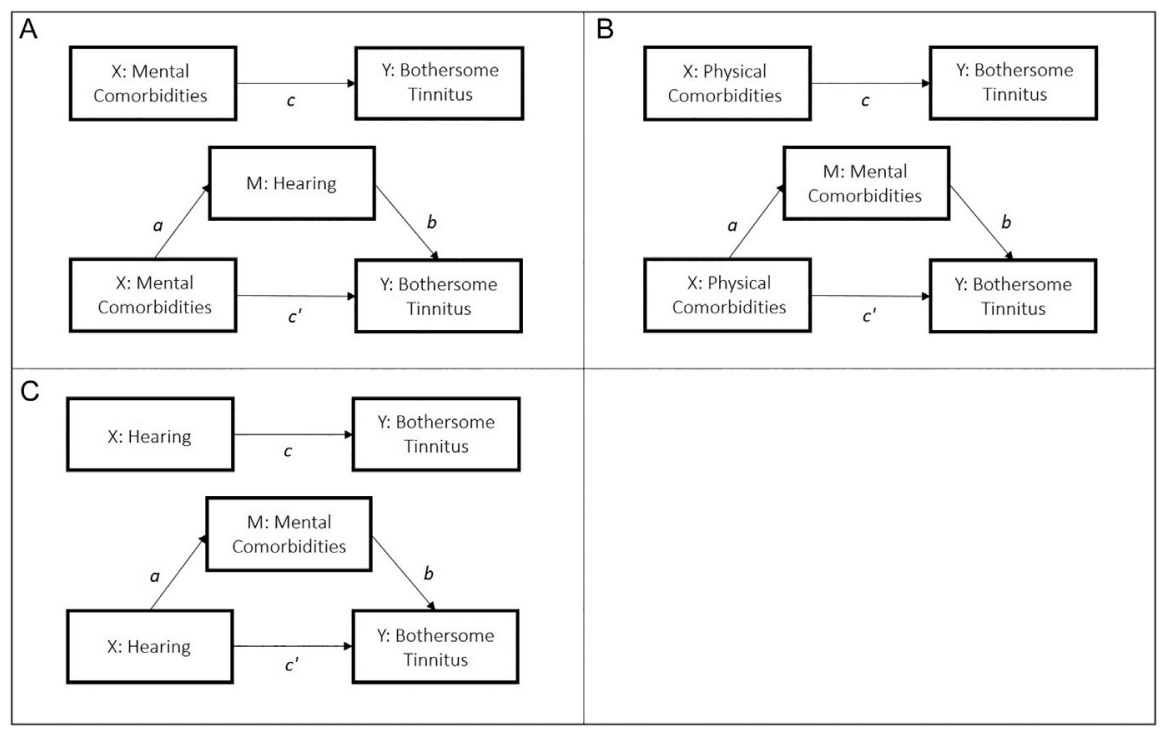

FIG. 1

Conceptual models of the performed mediation analyses. $\mathrm{X}=$ predictor, $\mathrm{M}=$ mediator, $Y=$ outcome. Coefficient $c$ designates the total effect of the respective $X$ on

$Y$ (ignoring $M$ ); coefficient $a$ is the effect of $X$ on $M$, coefficient $b$ is the effect of $M$ on $Y$ (controlling for $X$ ); coefficient $c^{\prime}$ designates the direct effect of $X$ on $Y$ when $M$ is controlled; and $a \times b$ reflects the indirect or mediation effect.

comorbidities mediated the relationship between physical comorbidities and bothersome tinnitus; and (C) if mental comorbidities mediated the relationship between subjective hearing ability and bothersome tinnitus (see Fig. 1). The following standardized coefficients were calculated: coefficient $c$ designates the total effect of the predictor variable on the outcome (ignoring the mediator); coefficient $a$ is the effect of the predictor on the mediator; coefficient $b$ is the effect of the mediator on the outcome (controlling for the predictor); and coefficient $c^{\prime}$ reflects the direct effect of the predictor on the outcome when the mediator is controlled for; see Fig. 1. The product of the coefficients $a$ and $b$ reflects the mediation effect (or indirect effect of the predictor on the outcome), which was divided by the total effect $c$ to calculate the percentage of the total effect being mediated (Baron and Kenny, 1986; Herr, 2006). The Aroian version of the Sobel test (Aroian, 1947) was used to assess significance, as suggested by Baron and Kenny (1986).

Response rates were high; $99.6 \%$ (6 variables) or $99.5 \%$ (18 variables) for physical and mental comorbidities, $97.6 \%$ for subjective hearing ability, and $83.8 \%$ for hearingrelated difficulties in social situations (and complete data for age and gender). Overall, $1.0 \%$ of values were missing. 


\section{Results}

\subsection{Descriptive analyses}

The proportion of female participants did not differ between participants with bothersome $(56.4 \%)$ and non-bothersome tinnitus (56.5\%). On average, participants with non-bothersome tinnitus were 35.26 years old $(S D=12.07$, median $=32)$, and participants with bothersome tinnitus were 41.16years old ( $S D=14.58$, median $=40), U=1,847,821, P<0.001$. Compared to participants with nonbothersome tinnitus, participants with bothersome tinnitus more often reported reduced subjective hearing ability $(A R s=16.9)$, more hearing-related difficulties in social situations $(A R s=11.3)$, higher frequencies of chronic shoulder pain $(A R s=6.6)$, hypertension $(A R=3.9)$, osteoarthritis $(A R s=5.3)$, cardiovascular disease $(A R s=4.6)$, thyroid disease $(A R s=4.0)$, hyperlipidemia $(A R s=4.6)$, fibromyalgia $(A R s=4.0)$, Ménière's disease $(A R s=4.0)$, as well as higher frequencies of depression $(A R s=3.9)$, burnout $(A R s=4.1)$, panic $(A R s=2.3)$, anxiety syndrome $(A R s=3.6)$, social anxiety $(A R s=4.0)$, and posttraumatic stress disorder $(A R s=2.3)$; see Table 3 .

\subsection{Logistic regression models}

The control variable age had significant influences in all three regression models (individuals with higher age had increased odds of reporting bothersome tinnitus), while gender showed no influence for the prediction of bothersome (vs. non-bothersome) tinnitus.

\subsubsection{Subjective hearing}

Both subjective hearing ability and hearing-related difficulties in social situations significantly predicted bothersome tinnitus (vs. non-bothersome tinnitus), $X^{2}(4)=$ 309.11, $P<0.001$, Nagelkerke $R^{2}=0.101, f=0.34$, see Table 4, model 1 .

\subsubsection{Physical comorbidities}

Of the investigated physical comorbidities, chronic shoulder pain, cardiovascular disease, thyroid disease, and Ménière's disease significantly predicted bothersome tinnitus (vs. non-bothersome tinnitus), $X^{2}(17)=182.12, P<0.001$, Nagelkerke $R^{2}=0.052, f=0.23$, see Table 4, model 2 .

\subsubsection{Mental comorbidities}

Of the investigated mental comorbidities, depression, anxiety syndrome, and social anxiety significantly predicted bothersome tinnitus (vs. non-bothersome tinnitus), $X^{2}(11)=166.26, P<0.001$, Nagelkerke $R^{2}=0.047, f=0.22$, see Table 4, model 3 .

\subsection{Logistic mediation models}

Standardized coefficients and standard errors of all significant mediation models can be found in Table 5 . 
Table 3 Frequencies of subjective hearing ability and hearing-related difficulties in social situations, physical and mental comorbidities in participants with non-bothersome and bothersome tinnitus.

\begin{tabular}{|c|c|c|c|c|}
\hline Variable & $\begin{array}{l}\text { Non- } \\
\text { bothersome } \\
\text { tinnitus }\end{array}$ & $\begin{array}{l}\text { Bothersome } \\
\text { tinnitus }\end{array}$ & $X^{2}$ & $\boldsymbol{P}$ \\
\hline \multicolumn{5}{|l|}{ Hearing } \\
\hline Subjective hearing ability*** & $N=6754$ & $N=676$ & 285.11 & $<0.001$ \\
\hline Good & $68.5 \%(4629)$ & $36.1 \%(244)$ & & \\
\hline Reduced & $31.5 \%(2125)$ & $63.9 \%(432)$ & & \\
\hline $\begin{array}{l}\text { Hearing-related difficulties } \\
\text { in social situations } * * *\end{array}$ & $N=5742$ & $N=637$ & 127.09 & $<0.001$ \\
\hline No & $44.5 \%(2557)$ & $21.2 \%(135)$ & & \\
\hline Yes & $55.5 \%(3185)$ & $78.8 \%(502)$ & & \\
\hline Physical comorbidities & $N=6882$ & $N=695$ & & \\
\hline Migraine & $14.8 \%(1016)$ & $16.7 \%(116)$ & 1.70 & 0.193 \\
\hline Chronic shoulder pain $* * *$ & $5.3 \%(367)$ & $11.5 \%(80)$ & 42.30 & $<0.001$ \\
\hline Osteoarthritis $* * *$ & $4.7 \%(323)$ & $9.4 \%(65)$ & 27.25 & $<0.001$ \\
\hline Fibromyalgia*** & $0.8 \%(54)$ & $2.3 \%(16)$ & 14.27 & $<0.001$ \\
\hline Epilepsy & $0.7 \%(47)$ & $1.3 \%(9)$ & 2.44 & 0.118 \\
\hline Rheumatoid arthritis & $0.6 \%(39)$ & $0.7 \%(5)$ & 0.06 & 0.808 \\
\hline Ménière's disease ${ }^{* * *}$ & $0.2 \%(13)$ & $1.0 \%(7)$ & 13.10 & $<0.001$ \\
\hline Systemic lupus erythematosus & $0.1 \%(5)$ & $0.0 \%(0)$ & $<0.00$ & 1 \\
\hline \multirow[t]{2}{*}{ Multiple sclerosis } & $0.1 \%(10)$ & $0.0 \%(0)$ & 0.21 & 0.647 \\
\hline & $N=6886$ & $N=695$ & & \\
\hline Asthma & $11.2 \%(774)$ & $11.9 \%(83)$ & 0.24 & 0.621 \\
\hline Hypertension $* * *$ & $5.8 \%(399)$ & $9.5 \%(66)$ & 14.39 & $<0.001$ \\
\hline Hyperlipidemia*** & $3.1 \%(211)$ & $6.3 \%(44)$ & 19.73 & $<0.001$ \\
\hline Cardiovascular disease ${ }^{* * *}$ & $4.0 \%(277)$ & $7.8 \%(54)$ & 20.34 & $<0.001$ \\
\hline Diabetes & $0.6 \%(41)$ & $0.6 \%(4)$ & $<0.00$ & 1 \\
\hline Thyroid disease $e^{* * *}$ & $3.6 \%(251)$ & $6.8 \%(47)$ & 15.43 & $<0.001$ \\
\hline Mental comorbidities & $N=6882$ & $N=695$ & & \\
\hline Depression*** & $20.4 \%(1405)$ & $26.8 \%(186)$ & 14.95 & $<0.001$ \\
\hline Burnout*** & $10.1 \%(697)$ & $15.1 \%(105)$ & 16.02 & $<0.001$ \\
\hline Panic* & $11.1 \%(763)$ & $14.0 \%(97)$ & 4.89 & 0.027 \\
\hline Anxiety syndrome ${ }^{* * *}$ & $10.0 \%(688)$ & $14.4 \%(100)$ & 12.60 & $<0.001$ \\
\hline Social anxiety*** & $3.4 \%(231)$ & $6.3 \%(44)$ & 15.13 & $<0.001$ \\
\hline Obsessive-compulsive disorder & $2.0 \%(140)$ & $2.7 \%(19)$ & 1.18 & 0.277 \\
\hline $\begin{array}{l}\text { Posttraumatic stress } \\
\text { disorder* }\end{array}$ & $1.6 \%(107)$ & $2.7 \%(19)$ & 4.67 & 0.031 \\
\hline Bipolar disease & $0.8 \%(52)$ & $1.0 \%(7)$ & 0.24 & 0.622 \\
\hline Agoraphobia & $0.6 \%(38)$ & $1.0 \%(7)$ & 1.51 & 0.219 \\
\hline
\end{tabular}

Note. Pearson $\mathrm{X}^{2}$ tests with continuity correction. Bold factors indicate significant differences in frequencies.

*** $\mathrm{P}<0.001, * * \mathrm{P}<0.01, * \mathrm{P}<0.05$. 
Table 4 Logistic regression models for the prediction of bothersome tinnitus (vs. non-bothersome tinnitus): subjective hearing (model 1 ), mental comorbidities (model 2), and physical comorbidities (model 3).

\begin{tabular}{|c|c|c|c|c|c|c|c|}
\hline Variable & $\beta$ & SE $\beta$ & $\begin{array}{l}\text { Wald's } \\
X^{2}\end{array}$ & $P$ & OR & \multicolumn{2}{|c|}{$95 \%-\mathrm{Cl}$} \\
\hline \multicolumn{8}{|l|}{ Model $1(N=6250)$} \\
\hline Constant & -3.96 & 0.15 & 668.25 & $<0.001$ & 0.02 & & \\
\hline Age*** & 0.02 & $<0.01$ & 55.41 & $<0.001$ & 1.02 & 1.02 & 1.03 \\
\hline \multicolumn{8}{|l|}{ Gender } \\
\hline $\begin{array}{l}\text { Subjective hearing } \\
\text { ability*** }\end{array}$ & 0.97 & 0.11 & 83.44 & $<0.001$ & 2.65 & 2.15 & 3.26 \\
\hline $\begin{array}{l}\text { Hearing-related } \\
\text { difficulties in social } \\
\text { situations*** }\end{array}$ & 0.48 & 0.12 & 16.25 & $<0.001$ & 1.61 & 1.28 & 2.04 \\
\hline \multicolumn{8}{|l|}{ Model $2(N=7577)$} \\
\hline Constant & -3.49 & 0.14 & 609.14 & $<0.001$ & 0.03 & & \\
\hline Age $* * *$ & 0.03 & $<0.01$ & 78.29 & $<0.001$ & 1.03 & 1.02 & 1.04 \\
\hline \multicolumn{8}{|l|}{ Gender } \\
\hline \multicolumn{8}{|l|}{ Migraine } \\
\hline \multicolumn{8}{|l|}{ Asthma } \\
\hline \multicolumn{8}{|l|}{ Hypertension } \\
\hline $\begin{array}{l}\text { Chronic shoulder } \\
\text { pain*** }\end{array}$ & 0.63 & 0.14 & 20.80 & $<0.001$ & 1.88 & 1.43 & 2.47 \\
\hline \multicolumn{8}{|l|}{ Osteoarthritis } \\
\hline Cardiovascular disease* & 0.40 & 0.16 & 6.07 & 0.014 & 1.49 & 1.08 & 2.04 \\
\hline Thyroid disease* & 0.39 & 0.17 & 5.19 & 0.023 & 1.48 & 1.06 & 2.08 \\
\hline \multicolumn{8}{|l|}{ Hyperlipidemia } \\
\hline \multicolumn{8}{|l|}{ Fibromyalgia } \\
\hline \multicolumn{8}{|l|}{ Epilepsy } \\
\hline \multicolumn{8}{|l|}{ Rheumatoid arthritis } \\
\hline \multicolumn{8}{|l|}{ Diabetes } \\
\hline Ménière's disease* & 1.23 & 0.50 & 6.14 & 0.013 & 3.42 & 1.29 & 9.05 \\
\hline \multicolumn{8}{|l|}{$\begin{array}{l}\text { Systemic lupus } \\
\text { erythematosus }\end{array}$} \\
\hline \multicolumn{8}{|l|}{ Multiple sclerosis } \\
\hline \multicolumn{8}{|l|}{ Model $3(N=7577)$} \\
\hline Constant & -3.75 & 0.14 & 727.39 & $<0.001$ & 0.02 & & \\
\hline$A g e^{* * *}$ & 0.04 & $<0.01$ & 141.57 & $<0.001$ & 1.04 & 1.03 & 1.04 \\
\hline Gender & & & & & & & \\
\hline Depression* & 0.22 & 0.11 & 3.91 & 0.048 & 1.25 & 1.00 & 1.56 \\
\hline Burnout & & & & & & & \\
\hline Panic & & & & & & & \\
\hline
\end{tabular}


Table 4 Logistic regression models for the prediction of bothersome tinnitus (vs. non-bothersome tinnitus): subjective hearing (model 1 ), mental comorbidities (model 2), and physical comorbidities (model 3).—cont'd

\begin{tabular}{|c|c|c|c|c|c|c|c|}
\hline Variable & $\beta$ & SE $\beta$ & $\begin{array}{l}\text { Wald's } \\
X^{2}\end{array}$ & $P$ & OR & \multicolumn{2}{|c|}{$95 \%-\mathrm{Cl}$} \\
\hline Anxiety syndrome* & 0.32 & 0.14 & 5.04 & 0.025 & 1.38 & 1.04 & 1.83 \\
\hline $\begin{array}{l}\text { Social anxiety* } \\
\text { Obsessive-compulsive } \\
\text { disorder }\end{array}$ & 0.45 & 0.19 & 5.50 & 0.019 & 1.57 & 1.08 & 2.30 \\
\hline $\begin{array}{l}\text { Posttraumatic stress } \\
\text { disorder }\end{array}$ & & & & & & & \\
\hline Bipolar disease & & & & & & & \\
\hline Agoraphobia & & & & & & & \\
\hline
\end{tabular}

Note. Only significant results are displayed. $O R=O d d s$ ratio.

*** $\mathrm{P}<0.001$, ** $\mathrm{P}<0.01$, * $\mathrm{P}<0.05$.

\subsubsection{X: Mental comorbidities, M: Subjective hearing, Y: Bothersome tinnitus (vs. non-bothersome tinnitus)}

Subjective hearing ability mediated $13 \%$ of the effect of depression on bothersome tinnitus, $P=0.020$, and $19 \%$ of the effect of social anxiety on bothersome tinnitus, $P=0.004$. Hearing-related difficulties in social situations mediated $36 \%$ of the effect of depression, $P<0.001,20 \%$ of the effect of anxiety syndrome, $P=0.001$, and $31 \%$ of the effect of social anxiety, $P<0.001$, on bothersome tinnitus.

\subsubsection{X: Physical comorbidities, M: Mental comorbidities, Y: Bothersome tinnitus (vs. non-bothersome tinnitus)}

Depression mediated 5\% of the effect of cardiovascular disease, $P=0.012$, and 5\% of the effect of thyroid disease, $P=0.019$, and $8 \%$ of the effect of chronic shoulder pain, $P=0.003$, on bothersome tinnitus. Anxiety syndrome mediated $5 \%$ of the effect of cardiovascular disease, $P=0.018$, and $7 \%$ of the effect of chronic shoulder pain, $P=0.006$, on bothersome tinnitus. Social anxiety mediated $6 \%$ of the effect of chronic shoulder pain, $P=0.007$, on bothersome tinnitus.

\subsubsection{X: Subjective hearing, M: Mental comorbidities, Y: Bothersome tinnitus (vs. non-bothersome tinnitus)}

Depression mediated $2 \%$ of the effect of hearing-related difficulties in social situations, $P=0.037$, on bothersome tinnitus. Anxiety syndrome mediated $2 \%$ of the effect of hearing-related difficulties in social situations, $P=0.034$, on bothersome tinnitus. Social anxiety mediated $2 \%$ of the effect of subjective hearing ability, $P=0.028$, and $4 \%$ of the effect of hearing-related difficulties in social situations, $P=0.007$, on bothersome tinnitus. 
Table 5 Standardized coefficients and standard errors of significant mediation effects.

\begin{tabular}{|c|c|c|c|c|c|c|c|c|c|}
\hline \multirow[t]{2}{*}{ Predictor $(\mathrm{X})$} & \multirow[t]{2}{*}{ Mediator (M) } & \multicolumn{2}{|c|}{$\begin{array}{l}\text { Effect of } \\
X \text { on } M\end{array}$} & \multicolumn{2}{|c|}{$\begin{array}{l}\text { Effect of } \\
M \text { on } Y \\
\text { controlled } \\
\text { for } X\end{array}$} & \multicolumn{2}{|c|}{$\begin{array}{l}\text { Effect of } \\
X \text { on } Y\end{array}$} & \multicolumn{2}{|c|}{$\begin{array}{l}\text { Effect of } X \text { on } \\
Y \text { controlled } \\
\text { for } M\end{array}$} \\
\hline & & $a$ & SE & $b$ & SE & $c$ & SE & $c^{\prime}$ & SE \\
\hline Depression & Subjective hearing ability & 0.032 & 0.013 & 0.331 & 0.021 & 0.079 & 0.020 & 0.063 & 0.020 \\
\hline Social anxiety & Subjective hearing ability & 0.039 & 0.013 & 0.330 & 0.021 & 0.068 & 0.017 & 0.059 & 0.017 \\
\hline Depression & $\begin{array}{l}\text { Hearing-related difficulties in } \\
\text { social situations }\end{array}$ & 0.100 & 0.014 & 0.282 & 0.026 & 0.079 & 0.020 & 0.046 & 0.021 \\
\hline Anxiety syndrome & $\begin{array}{l}\text { Hearing-related difficulties in } \\
\text { social situations }\end{array}$ & 0.049 & 0.014 & 0.284 & 0.026 & 0.070 & 0.019 & 0.055 & 0.020 \\
\hline Social anxiety & $\begin{array}{l}\text { Hearing-related difficulties in } \\
\text { social situations }\end{array}$ & 0.075 & 0.016 & 0.282 & 0.026 & 0.068 & 0.017 & 0.059 & 0.018 \\
\hline Cardiovascular disease & Depression & 0.050 & 0.014 & 0.075 & 0.020 & 0.078 & 0.017 & 0.075 & 0.017 \\
\hline Thyroid disease & Depression & 0.044 & 0.014 & 0.076 & 0.020 & 0.070 & 0.018 & 0.067 & 0.018 \\
\hline Chronic shoulder pain & Depression & 0.140 & 0.013 & 0.063 & 0.021 & 0.108 & 0.017 & 0.100 & 0.017 \\
\hline Cardiovascular disease & Anxiety syndrome & 0.059 & 0.017 & 0.066 & 0.019 & 0.078 & 0.017 & 0.076 & 0.017 \\
\hline Chronic shoulder pain & Anxiety syndrome & 0.126 & 0.016 & 0.057 & 0.020 & 0.108 & 0.017 & 0.102 & 0.017 \\
\hline Chronic shoulder pain & Social anxiety & 0.106 & 0.025 & 0.062 & 0.017 & 0.108 & 0.017 & 0.104 & 0.017 \\
\hline $\begin{array}{l}\text { Hearing-related difficulties in } \\
\text { social situations }\end{array}$ & Depression & 0.121 & 0.017 & 0.046 & 0.021 & 0.285 & 0.026 & 0.282 & 0.026 \\
\hline $\begin{array}{l}\text { Hearing-related difficulties in } \\
\text { social situations }\end{array}$ & Anxiety syndrome & 0.079 & 0.023 & 0.055 & 0.020 & 0.285 & 0.026 & 0.284 & 0.026 \\
\hline $\begin{array}{l}\text { Hearing-related difficulties in } \\
\text { social situations }\end{array}$ & Social anxiety & 0.196 & 0.040 & 0.059 & 0.018 & 0.285 & 0.026 & 0.282 & 0.026 \\
\hline Subjective hearing ability & Social anxiety & 0.099 & 0.033 & 0.059 & 0.017 & 0.333 & 0.021 & 0.330 & 0.021 \\
\hline
\end{tabular}

Note. $X=$ predictor, $M=$ mediator, $Y=$ outcome (bothersome tinnitus). 


\section{Discussion}

\subsection{Prevalence}

The prevalence of bothersome tinnitus $(N=697)$ was $2.2 \%$ in the total population sample and $9.2 \%$ in the tinnitus sample. Many studies found similar prevalence rates $(1.2-3 \%)$ of bothersome tinnitus in the population (Gallus et al., 2015; Michikawa et al., 2010; Nondahl et al., 2011), while others report higher rates of 5.8-7\% (Park et al., 2014; Ramage-Morin et al., 2019). This variance might result from the different study populations as well as from the varying definitions of "bothersome" tinnitus: tinnitus posing a big or very big problem (Gallus et al., 2015), tinnitus interfering with concentration or sleep (Michikawa et al., 2010), tinnitus in its worst form being severe (Nondahl et al., 2011), tinnitus in daily life being annoying (irritating) or severely annoying and causing sleep problems (Park et al., 2014), or tinnitus being bothering by affecting sleep, concentration or mood (Ramage-Morin et al., 2019).

\subsection{Age and gender}

The prevalence of bothersome tinnitus did not differ between genders. This is in accordance with other studies that report equal rates of bothersome or frequent tinnitus in both genders (Axelsson and Ringdahl, 1989; Park et al., 2014; Shargorodsky et al., 2010). However, conflicting findings exist as well (McCormack et al., 2016). The relationship between older age and bothersome tinnitus is consistent with several other findings (Gallus et al., 2015; Kim et al., 2015; Park et al., 2014; Shargorodsky et al., 2010), but not all (Jalessi et al., 2013). In addition, we found distinct effects of both higher age and reduced subjective hearing ability on bothersome tinnitus in the regression analysis. Higher age might therefore increase the risk of bothersome tinnitus independently of age-related hearing loss-for example via age-related life changes that can negatively affect the quality of life (e.g., functional loss), which may in turn increase tinnitus-related distress (Henry et al., 2005).

\subsection{Subjective hearing}

Reduced hearing ability $(\mathrm{OR}=2.65[2.15,3.26])$ was associated with bothersome tinnitus, in accordance with other cross-sectional population studies (Kim et al., 2015; Park et al., 2014; Shargorodsky et al., 2010). In addition, we found an effect of hearing-related difficulties in social situations $(\mathrm{OR}=1.61[1.28,2.04])$. Of the three regression models, subjective hearing (model 1) showed the highest goodness-offit (Nagelkerke $R^{2}=0.101$ ), with a medium effect size $(f=0.34)$, in the prediction of bothersome vs. non-bothersome tinnitus. Hearing impairment may exert direct influences on tinnitus-related distress as well as indirect ones via increased psychological distress in social situations, possibly leading to impaired social functioning. 
Previous research found that $45 \%$ of individuals with bothersome tinnitus report a weak sense of community belonging (Ramage-Morin et al., 2019), highlighting the importance to address social functioning in treatment interventions.

The effects of hearing-related difficulties in social situations on bothersome tinnitus were partially mediated by depression (2\%), anxiety syndrome (2\%), and social anxiety (4\%). The latter also partially mediated the effects of subjective hearing impairment $(2 \%)$. On the other hand, subjective hearing ability partially mediated the effects of depression (13\%) and social anxiety (19\%) on bothersome tinnitus. Moreover, hearing-related difficulties in social situations mediated the effects of depression (36\%), anxiety syndrome (20\%), and social anxiety (31\%) on bothersome tinnitus by a large degree. These results suggest that impaired subjective hearing ability and hearing-related difficulties in social situations exert indirect effects on bothersome tinnitus through their impact on emotional factors. At the same time, mental comorbidities seem to exert indirect effects on bothersome tinnitus through their impact on subjective hearing ability and hearingrelated difficulties in social situations. Hearing and emotional factors hence appear highly interconnected.

These results implicate the need for thorough distinctions between subjective and objective hearing ability. With objective hearing loss, hearing aid provision in tinnitus patients may reduce tinnitus-related distress not only through direct effects of improved hearing but also through minimizing the negative effects of reduced hearing ability on emotional wellbeing (e.g., due to social withdrawal). In contrast, subjective hearing impairment might represent a coping strategy under depressogenic strain. Moreover, emotional factors can influence the way hearing impairment is dealt with by the affected individual and may, for example, underlie the disinclination to wear hearing aids. Given the strong interrelationships between subjective hearing and mental symptoms, measures to restore hearing and psychological interventions should ideally be combined to stimulate mutual transfer effects.

\subsection{Physical comorbidities}

Cardiovascular disease $(\mathrm{OR}=1.49[1.08,2.04])$, chronic shoulder pain $(\mathrm{OR}=1.88$ $[1.43,2.47])$, thyroid disease $(\mathrm{OR}=1.48[1.06,2.08])$, and Ménière's disease $(\mathrm{OR}=3.42[1.29,9.05])$ were associated with the presence of bothersome (vs. nonbothersome) tinnitus. For the physical comorbidities model (model 2), the effect size was small $(f=0.23)$.

Associations between cardiovascular diseases and tinnitus have been reported in the literature, e.g., for congestive heart failure in elderly patients (Borghi et al., 2011), or coronary artery disease in different study populations (Fujii et al., 2011; Lin et al., 2018; Michikawa et al., 2010). In line with our result, some studies found specific relationships of cardiovascular diseases with bothersome tinnitus. In a crosssectional study, Park et al. (2014) found a strong effect of a history of cardiovascular disease for the prediction of annoying tinnitus after multivariable adjustment. Nondahl 
et al. (2002) found an association between a history of cardiovascular disease and the prevalence of "significant" tinnitus (at least moderately severe and/or causing sleep problems), as well as a predictive association between higher cholesterol levels (a cardiovascular risk factor) and the 5-year incidence of "significant" tinnitus. Stobik et al. (2005) found higher rates of cardiovascular diseases among patients with severe (decompensated) tinnitus than those with mild (compensated) tinnitus. Moreover, cardiovascular disease and depression are interrelated, and evidence exists for biological and behavioral mechanisms linking both conditions (Seligman and Nemeroff, 2015). In the present study, the effects of cardiovascular disease on bothersome tinnitus were partially mediated by depression $(5 \%)$ and anxiety syndrome (5\%), highlighting the importance of considering psychological factors in somatic conditions.

In line with our findings, Kuttila et al. (2005) found that shoulder pain is predictive of recurrent tinnitus. In their general population sample, 53\% of individuals with recurrent tinnitus reported shoulder ache at least twice a month. Two other (relatively old) studies that report findings on shoulder pain and tinnitus cannot be interpreted clearly because of confounding issues. Bjorne and Agerberg (1996) found that patients with Ménière's disease more often report neck or shoulder pain than control subjects, yet this difference might be attributable to other symptoms in the patient group than tinnitus. Ren and Isberg (1995) found higher frequencies of back or shoulder pain in patients with tinnitus and internal derangement of the temporomandibular joint than a control group, but in their sample, this difference might be explained by age. As we controlled for age in our analyses, our findings suggest an age-independent effect of shoulder pain. However, the presence of temporomandibular joint dysfunction was not assessed in our sample. Moreover, research on neck and shoulder pain has identified psychosocial risk factors, e.g., psychological distress (Menendez et al., 2015; Siivola et al., 2004; Skov et al., 1996), and evidence suggests positive effects of psychosocial interventions for the management of musculoskeletal pain (Babatunde et al., 2017). Thus, links between bothersome tinnitus and shoulder pain are likely to be influenced by psychological factors and our result supports this notion, as effects of chronic shoulder pain on bothersome tinnitus were partially mediated by depression $(8 \%)$, anxiety syndrome $(7 \%)$, and social anxiety $(6 \%)$.

Previous research found an association between tinnitus and thyroid diseases (Kim et al., 2015). Furthermore, causal relationships between hypothyroidism and hearing loss are known (Anand et al., 1989; Coelho et al., 2020; Mahafzah et al., 2018; Malik et al., 2002; Sharlin et al., 2018; Uziel et al., 1985). Tinnitus was found to improve in 57\% (Malik et al., 2002) or 62\% (Singh et al., 2019) of patients with hypothyroidism after thyroxine substitution therapy. Moreover, thyroid function and depression are related; both hypothyroidism and hyperthyroidism can lead to depressive symptoms, and depression can also be associated with subclinical thyroid abnormalities (Hage and Azar, 2012). Consistent with these connections, we found that the effects of thyroid disease on bothersome tinnitus were partially mediated by depression $(5 \%)$. 
Furthermore, our findings suggest that tinnitus in individuals with Ménière's disease might be perceived as particularly bothersome. The effect of Ménière's disease was the strongest of all predictors with an OR of 3.42-indicating that the risk of bothersome compared to non-bothersome tinnitus is three times higher in individuals with Ménière's disease than in individuals without the disease. This effect is in line with a previous report of more severe tinnitus in patients with Ménière's disease compared to patients with tinnitus and noise-induced or age-related hearing loss (Stouffer and Tyler, 1990). Moreover, in a sample of patients with long-standing Ménière's disease, tinnitus was rated by $19 \%$ as their most severe symptom, and $10 \%$ reported a severe or very severe impact of tinnitus on their life (Yoshida et al., 2011). In a cross-sectional study, higher tinnitus severity was associated with advanced stages of Ménière's disease/higher levels of hearing loss (Romero Sánchez et al., 2010). The impact of tinnitus also seems to be influenced by other symptoms of Ménière's disease such as aural pressure and gait problems (Yoshida et al., 2011). Our analysis revealed no mediating effects of psychological symptoms on the relationship between Ménière's disease and bothersome tinnitus. This might suggest that the presence of other symptoms of Ménière's disease is more relevant for tinnitus severity in these patients than psychological symptoms.

In sum, cardiovascular disease, chronic shoulder pain, and thyroid disease seem not only to exert direct influences on bothersome tinnitus but also indirect ones through their associations with emotional factors.

\subsection{Mental comorbidities}

Depression $(\mathrm{OR}=1.25[1.00,1.56])$, anxiety syndrome $(\mathrm{OR}=1.38[1.04,1.83])$, and social anxiety $(\mathrm{OR}=1.57[1.08,2.30])$ were associated with the presence of bothersome (vs. non-bothersome) tinnitus. For the mental comorbidities model (model 3), the effect size was small $(f=0.22)$.

These results are consistent with a systematic review by Pinto et al. (2014) who concluded that the comorbid presence of anxiety or depression is associated with higher tinnitus severity and annoyance. The relationship between mental illness and tinnitus is bidirectional, as mental conditions may impair the stress tolerance and thus lead to higher distress in tinnitus patients; tinnitus-related distress on the other hand can lead to psychological symptoms or increase the severity of preexisting ones (Pinto et al., 2014; Ziai et al., 2017).

Our results suggest that depression and anxiety can aggravate negative hearingrelated effects and negative effects of physical symptoms on bothersome (vs. nonbothersome) tinnitus. These findings implicate that states of emotional distress are important treatment targets in individuals with bothersome tinnitus. The improvement of affective and anxiety symptoms by psychological treatment interventions like cognitive-behavioral therapy (CBT) is likely to exert not only direct effects on tinnitus-related distress but also indirect ones by reducing negative influences of physical symptoms, subjective hearing impairment, or hearing-related difficulties in social situations. 


\subsection{Clinical implications}

Our findings point to the issue that the distinction between physical and mental conditions is not as clear as suggested by diagnostic classification systems, since many conditions share both physical and psychological aspects. Generally, three different relationships between chronic physical diseases and mental conditions are possible (Turner and Kelly, 2000): (1) Chronic physical diseases can lead to the manifestation of mental conditions, often depression or anxiety. (2) In individuals with pre-existing mental conditions, the development of a chronic physical disease can aggravate their symptoms. (3) If physical symptoms in individuals with chronic diseases worsen or new ones develop, this can constitute an expression of emotional distress (Turner and Kelly, 2000). In the clinical care of chronic tinnitus patients, these possible connections between tinnitus and mental health need to be addressed.

Furthermore, recent literature has begun to address the limitations of traditional diagnostic classification systems for mental disorders which classify psychopathology in distinct categories that are not based on evidence (Hofmann, 2014; Kotov et al., 2017). New approaches include empirically-based frameworks such as structural approaches using dimensional classification (Kotov et al., 2017), theory-based cognitive behavior classifications (Hofmann, 2014), or network approaches (Fried et al., 2017).

Dimensional classification approaches are based on the assumption that psychopathology lies on a continuum and can be described by different dimensions in a systematic hierarchy (Kotov et al., 2017; Lahey et al., 2017). It has been proposed that a hierarchical taxonomy consisting of a general psychopathology factor encompassing several dimensions/spectra (internalizing, thought disorder, disinhibited externalizing, antagonistic externalizing, detachment, and somatoform) comprised of different syndromes is suitable to characterize the majority of psychopathology (Kotov et al., 2017). In line with this approach, Ivansic et al. (2019) found that mental health in tinnitus patients can best be described by a general psychopathology factor and a somatization factor. They found that the expression of the general psychopathology factor was as high in severe tinnitus as in depressed patients, but more pronounced in mild tinnitus than in healthy controls. The somatization factor, on the other hand, was higher in both mild and severe tinnitus than in depressed patients or healthy controls (Ivansic et al., 2019).

The cognitive-behavioral approach, on which CBT is built, looks at psychopathology as complex causal networks (Hofmann, 2014). In this framework, certain triggers (moderated by attentional processes and trait cognitions) can activate maladaptive cognitive processes, which in turn lead to psychological distress manifesting as a specific interplay of subjective experiences, physiological symptoms, and behavioral responses (Hofmann, 2014). The focus of this approach lies on cognitive processes and their consequences for emotion regulation, which have proven to be important—and modifiable by CBT - for many different mental conditions (Hofmann et al., 2012; Hofmann, 2014). CBT also is known to have a positive effect on tinnitus management (Martinez-Devesa et al., 2010). 
In a similar approach, the network perspective conceptualizes psychopathology as complex dynamic networks of mutually interacting symptoms (Fried et al., 2017). In this conceptualization, comorbidity between different mental conditions is thought to be explained by interactions between symptoms, in that the presence of a specific disorder can lead to the manifestation of another disorder via bridge symptoms (Fried et al., 2017). With this approach, the high comorbidity among severe tinnitus and mental disorders could potentially be explained by shared bridge symptoms (e.g., insomnia, concentration problems). Moreover, network approaches have the potential to predict transitions from a healthy network state to a disease state (Fried et al., 2017; van de Leemput et al., 2014), e.g., from mild to severe tinnitusrelated distress, which has high clinical relevance.

In sum, all of these approaches appear suitable to better conceptualize tinnitusrelated distress (emotions, cognitions, reactions), comorbid mental and physical symptoms, and their interrelationships than current diagnostic classification systems. In line with Stobik et al. (2005), we argue that bothersome tinnitus should be understood as a complex psychosomatic phenomenon including somatic, auditory, and psychosocial aspects, which can mutually reinforce each other. Consistent with this view, our results implicate the need for multimodal psychosomatic treatment for bothersome tinnitus in an interdisciplinary setting. Treatment-induced reductions of affective or anxiety symptoms by CBT can directly improve tinnitus-related distress as well as reduce negative effects of comorbid physical symptoms and hearingrelated effects, whereas measures to restore hearing impairment have the potential to decrease aggravated negative effects of mental symptoms. Thus, multimodal treatment approaches combining psychological interventions, hearing aid provision, and medical treatment of comorbid physical symptoms appear to have the highest clinical potential to alleviate tinnitus-related distress.

\subsection{Limitations}

Limitations of this study include its cross-sectional design and the fact that all variables were measured via self-report and single-item questions. Validated information on medical diagnoses, objective data from audiometric testing, and standardized assessment of tinnitus burden via psychometric questionnaires would constitute preferable sources in terms of reliability and validity. Moreover, other psychological factors known to be related to bothersome tinnitus, e.g., coping styles or cognitive factors, could not be investigated in this study as they were not assessed by the survey. However, we expect that the inclusion of such factors would have improved the prediction of bothersome (vs. non-bothersome tinnitus), rather than changing the nature of our results. As the sample was large, heterogeneous, and, for some part, randomly recruited from the general population, selection biases do not seem likely. However, distorting influences based on self-selection by spontaneous online registration cannot be excluded. Moreover, results might not extend to other cultural contexts. Overall, the magnitude of the effects was rather small (the effect sizes of the regression models were small or medium, and the highest percentage of an effect being mediated was $36 \%$ ). 


\subsection{Conclusion}

Psychological factors and hearing-related difficulties play key roles in predicting bothersome tinnitus (vs. non-bothersome tinnitus) in a large population sample. As hypothesized, our results suggest that psychological factors partially contribute to explaining the impact of physical comorbidities and hearing-related effects on bothersome tinnitus. This highlights their transdiagnostic importance for aggravating varied physical symptom clusters and offers useful targets for psychological treatment strategies. Subjective hearing impairment and hearing-related difficulties in social situations, on the other hand, seem to partially explain the impact of mental comorbidities on bothersome tinnitus. Overall, these findings implicate the need for interdisciplinary multimodal treatment approaches for patients with bothersome tinnitus, combining psychological interventions, the provision of hearing aids, and medical treatment of comorbid physical symptoms in order to achieve the highest clinical efficacy.

\section{Acknowledgments}

This project has received funding from the European Research Council (ERC) under the European Union's Horizon 2020 research and innovation programme (Grant agreement no 764604).

\section{Conflict of interest}

CC is supported by the UK National Institute for Health Research (NIHR) Biomedical Research Centre but the views expressed herein are his own and do not represent those of NIHR nor the UK Department of Health and Social Care. The remaining authors declare that the research was conducted in the absence of any commercial or financial relationships that could be construed as a potential conflict of interest.

\section{Data availability statement}

Requests to access the datasets should be directed to Nancy Pedersen: nancy.pedersen@ki.se. Restrictions are based on the Swedish Act (2013:794) requiring that a valid ethical approval is obtained in Sweden.

\section{References}

Almqvist, C., Adami, H.-O., Franks, P.W., Groop, L., Ingelsson, E., Kere, J., Lissner, L., Litton, J.-E., Maeurer, M., Michaëlsson, K., Palmgren, J., Pershagen, G., Ploner, A., Sullivan, P.F., Tybring, G., Pedersen, N.L., 2011. LifeGene-a large prospective population-based study of global relevance. Eur. J. Epidemiol. 26, 67-77. https://doi. org/10.1007/s10654-010-9521-x. 
Anand, V.T., Mann, S.B., Dash, R.J., Mehra, Y.N., 1989. Auditory investigations in hypothyroidism. Acta Otolaryngol. 108, 83-87. https://doi.org/10.3109/00016488909107396.

Andersson, G., Carlbring, P., Kaldo, V., Ström, L., 2004. Screening of psychiatric disorders via the internet. A pilot study with tinnitus patients. Nord. J. Psychiatry 58, 287-291. https://doi.org/10.1080/08039480410005792.

Aroian, L.A., 1947. The probability function of the product of two normally distributed variables. Ann. Math. Stat. 18, 265-271. https://doi.org/10.1214/aoms/1177730442.

Axelsson, A., Ringdahl, A., 1989. Tinnitus - a study of its prevalence and characteristics. Br. J. Audiol. 23, 53-62. https://doi.org/10.3109/03005368909077819.

Babatunde, O.O., Jordan, J.L., Van der Windt, D.A., Hill, J.C., Foster, N.E., Protheroe, J., 2017. Effective treatment options for musculoskeletal pain in primary care: a systematic overview of current evidence. PLoS One 12, 1-30, e0178621. https://doi.org/10.1371/ journal.pone.0178621.

Baigi, A., Oden, A., Almlid-Larsen, V., Barrenäs, M.-L., Holgers, K.-M., 2011. Tinnitus in the general population with a focus on noise and stress: a public health study. Ear Hear. 32, 787-789. https://doi.org/10.1097/AUD.0b013e31822229bd.

Baron, R.M., Kenny, D.A., 1986. The moderator-mediator variable distinction in social psychological research: conceptual, strategic, and statistical considerations. J. Pers. Soc. Psychol. 51, 1173-1182. https://doi.org/10.1037/0022-3514.51.6.1173.

Basso, L., Boecking, B., Brueggemann, P., Pedersen, N.L., Canlon, B., Cederroth, C.R., Mazurek, B., 2020. Gender-specific risk factors and comorbidities of bothersome tinnitus. Front. Neurosci. 14, 1-15, Article No. 706. https://doi.org/10.3389/fnins. 2020.00706.

Belli, S., Belli, H., Bahcebasi, T., Ozcetin, A., Alpay, E., Ertem, U., 2008. Assessment of psychopathological aspects and psychiatric comorbidities in patients affected by tinnitus. Eur. Arch. Otorhinolaryngol. 265, 279-285. https://doi.org/10.1007/s00405-0070440-8.

Beukes, E.W., Manchaiah, V., Andersson, G., Allen, P.M., Terlizzi, P.M., Baguley, D.M., 2018. Situationally influenced tinnitus coping strategies: a mixed methods approach. Disabil. Rehabil. 40, 2884-2894. https://doi.org/10.1080/09638288.2017.1362708.

Bjorne, A., Agerberg, G., 1996. Craniomandibular disorders in patients with Menière's disease: a controlled study. J. Orofac. Pain 10, 28-37.

Borghi, C., Cosentino, E.R., Rinaldi, E.R., Brandolini, C., Rimondi, M.C., Veronesi, M., et al., 2011. Tinnitus in elderly patients and prognosis of mild-to-moderate congestive heart failure: a cross-sectional study with a long-term extension of the clinical follow-up. BMC Med. 9, 1-8, Article No. 80. https://doi.org/10.1186/1741-7015-9-80.

Borsook, D., Youssef, A.M., Simons, L., Elman, I., Eccleston, C., 2018. When pain gets stuck: the evolution of pain chronification and treatment resistance. Pain 159, 2421-2436. https:// doi.org/10.1097/j.pain.0000000000001401.

Brueggemann, P., Szczepek, A., Rose, M., McKenna, L., Olze, H., Mazurek, B., 2016. Impact of multiple factors on the degree of tinnitus distress. Front. Hum. Neurosci. 10, 1-11, Article No. 341. https://doi.org/10.3389/fnhum.2016.00341.

Brueggemann, P., Seydel, C., Schaefer, C., Szczepek, A.J., Amarjargal, N., Boecking, B., et al., 2019. ICD-10 symptom rating questionnaire for assessment of psychological comorbidities in patients with chronic tinnitus. HNO 67, 178-183. https://doi.org/10.1007/ s00106-019-0625-7.

Budd, R.J., Pugh, R., 1996. Tinnitus coping style and its relationship to tinnitus severity and emotional distress. J. Psychosom. Res. 41, 327-335. https://doi.org/10.1016/S0022-3999 (96)00171-7. 
Caldirola, D., Teggi, R., Daccò, S., Sangiorgio, E., Bussi, M., Perna, G., 2016. Role of worry in patients with chronic tinnitus and sensorineural hearing loss: a preliminary study. Eur. Arch. Otorhinolaryngol. 273, 4145-4151. https://doi.org/10.1007/s00405-016-4100-8.

Cil, Ö.Ç., Zateri, C., Güçlü, O., Oymak, S., Tezcan, E., 2020. The effect of fibromyalgia treatment on tinnitus. Am. J. Otolaryngol. 41, 102390. https://doi.org/10.1016/j.amjoto.2020.102390.

Ciminelli, P., Machado, S., Palmeira, M., Carta, M.G., Beirith, S.C., Nigri, M.L., et al., 2018. Tinnitus: the sound of stress? Clin. Pract. Epidemiol. Ment. Health 14, 264-269. https:// doi.org/10.2174/1745017901814010264.

Coebergh, J.A.F., Lauw, R.F., Sommer, I.E.C., Blom, J.D., 2019. Musical hallucinations and their relation with epilepsy. J. Neurol. 266, 1501-1515. https://doi.org/10.1007/s00415019-09289-x.

Coelho, C.B., Santos, R., Campara, K.F., Tyler, R., 2020. Classification of tinnitus. Otolaryngol. Clin. North Am. 53, 515-529. https://doi.org/10.1016/j.otc.2020.03.015.

Cohen, J., 1992. A power primer. Psychol. Bull. 112, 155-159. https://doi.org/10.1037/00332909.112.1.155.

Cohen, J., 1988. Statistical Power Analysis for the Behavioral Sciences. L. Erlbaum Associates, Hillsdale, NJ.

Daugherty, W.T., Lederman, R.J., Nodar, R.H., Conomy, J.P., 1983. Hearing loss in multiple sclerosis. Arch. Neurol. 40,33-35. https://doi.org/10.1001/archneur.1983.04050010053013.

Di Stadio, A., Ralli, M., 2017. Systemic lupus erythematosus and hearing disorders: literature review and meta-analysis of clinical and temporal bone findings. J. Int. Med. Res. 45, 1470-1480. https://doi.org/10.1177/0300060516688600.

Fagelson, M.A., 2007. The association between tinnitus and posttraumatic stress disorder. Am. J. Audiol. 16, 107-117. https://doi.org/10.1044/1059-0889(2007/015).

Figueiredo, R.R., de Azevedo, A.A., Penido, N.O., 2015. Tinnitus and arterial hypertension: a systematic review. Eur. Arch. Otorhinolaryngol 272, 3089-3094. https://doi.org/10.1007/ s00405-014-3277-y.

Figueiredo, R.R., de Azevedo, A.A., Penido, N.O., 2017. Ménière's disease and tinnitus. In: Fayez, B. Jr. (Ed.), Up to Date on Meniere's Disease. https://doi.org/10.5772/66390.

Fischer, C., Mauguière, F., Ibanez, V., Confavreux, C., Chazot, G., 1985. The acute deafness of definite multiple sclerosis: Baep patterns. Electroencephalogr. Clin. Neurophysiol. 61, 7-15. https://doi.org/10.1016/0013-4694(85)91066-1.

Folmer, R.L., Griest, S.E., Martin, W.H., 2008. Obsessive-compulsiveness in a population of tinnitus patients. Int. Tinnitus J. 14, 127-130.

Fried, E.I., van Borkulo, C.D., Cramer, A.O.J., Boschloo, L., Schoevers, R.A., Borsboom, D., 2017. Mental disorders as networks of problems: a review of recent insights. Soc. Psychiatry Psychiatr. Epidemiol. 52, 1-10. https://doi.org/10.1007/s00127-016-1319-z.

Fujii, K., Nagata, C., Nakamura, K., Kawachi, T., Takatsuka, N., Oba, S., et al., 2011. Prevalence of tinnitus in community-dwelling Japanese adults. J. Epidemiol. 21, 299-304. https://doi.org/10.2188/jea.JE20100124.

Gallus, S., Lugo, A., Garavello, W., Bosetti, C., Santoro, E., Colombo, P., Perin, P., La Vecchia, C., Langguth, B., 2015. Prevalence and determinants of tinnitus in the Italian adult population. Neuroepidemiology 45, 12-19. https://doi.org/10.1159/000431376.

Geocze, L., Mucci, S., Abranches, D.C., de Marco, M.A., de Penido, N.O., 2013. Systematic review on the evidences of an association between tinnitus and depression. Braz. J. Otorhinolaryngol. 79, 106-111. https://doi.org/10.5935/1808-8694.20130018. 
Gibrin, P.C.D., Melo, J.J., Marchiori, L.L.d.M., 2013. Prevalence of tinnitus complaints and probable association with hearing loss, diabetes mellitus and hypertension in elderly. CoDAS 25, 176-180. https://doi.org/10.1590/S2317-17822013000200014.

Guichard, E., Montagni, I., Tzourio, C., Kurth, T., 2016. Association between headaches and tinnitus in young adults: cross-sectional study. Headache 56, 987-994. https://doi.org/ 10.1111/head.12845.

Hage, M.P., Azar, S.T., 2012. The link between thyroid function and depression. J. Thyroid Res. 2012, 1-8. https://doi.org/10.1155/2012/590648.

Hamed, S.A., Oseilly, A.M., 2018. Cochlear function in adults with epilepsy and treated with carbamazepine. Audiol. Neurootol. 23, 63-72. https://doi.org/10.1159/ 000490232.

Hasson, D., Theorell, T., Wallén, M.B., Leineweber, C., Canlon, B., 2011. Stress and prevalence of hearing problems in the Swedish working population. BMC Public Health 11 (1), 130. https://doi.org/10.1186/1471-2458-11-130.

Hébert, S., Canlon, B., Hasson, D., 2012. Emotional exhaustion as a predictor of tinnitus. Psychother. Psychosom. 81, 324-326. https://doi.org/10.1159/000335043.

Henry, J.A., Dennis, K.C., Schechter, M.A., 2005. General review of tinnitus: prevalence, mechanisms, effects, and management. J. Speech Lang. Hear. Res. 48, 1204-1235. https://doi.org/10.1044/1092-4388(2005/084).

Herr, N.R., 2006. Mediation with Dichotomous Outcomes. viewed 25 February 2020. http:// web.archive.org/web/20200202182013/http://nrhpsych.com/mediation/logmed.html.

Herr, R.M., Loerbroks, A., Bosch, J.A., Seegel, M., Schneider, M., Schmidt, B., 2016. Associations of organizational justice with tinnitus and the mediating role of depressive symptoms and burnout-findings from a cross-sectional study. Int. J. Behav. Med. 23, 190-197. https://doi.org/10.1007/s12529-015-9505-z.

Hinton, D.E., Chhean, D., Pich, V., Hofmann, S.G., Barlow, D.H., 2006. Tinnitus among Cambodian refugees: relationship to PTSD severity. J. Trauma. Stress 19, 541-546. https://doi.org/10.1002/jts.20138.

Hoekstra, C.E.L., Wesdorp, F.M., van Zanten, G.A., 2014. Socio-demographic, health, and tinnitus related variables affecting tinnitus severity. Ear Hear. 35, 544-554. https://doi. org/10.1097/AUD.0000000000000045.

Hofmann, S.G., 2014. Toward a cognitive-behavioral classification system for mental disorders. Behav. Ther. 45, 576-587. https://doi.org/10.1016/j.beth.2014.03.001.

Hofmann, S.G., Asnaani, A., Vonk, I.J.J., Sawyer, A.T., Fang, A., 2012. The efficacy of cognitive behavioral therapy: a review of meta-analyses. Cogn. Ther. Res. 36, 427-440. https://doi.org/10.1007/s10608-012-9476-1.

Holgers, K.-M., Zöger, S., Svedlund, K., 2005. Predictive factors for development of severe tinnitus suffering-further characterization. Int. J. Audiol. 44, 584-592. https://doi.org/ $10.1080 / 14992020500190235$.

Hwang, J.H., Tsai, S.J., Liu, T.C., Chen, Y.C., Lai, J.T., 2018. Association of tinnitus and other cochlear disorders with a history of migraines. JAMA Otolaryngol. Head Neck Surg 144, 712-717. https://doi.org/10.1001/jamaoto.2018.0939.

Iikuni, F., Nomura, Y., Goto, F., Murakami, M., Shigihara, S., Ikeda, M., 2013. Why do patients with fibromyalgia complain of ear-related symptoms? Ear-related symptoms and otological findings in patients with fibromyalgia. Clin. Rheumatol. 32, 1437-1441. https://doi.org/10.1007/s10067-013-2287-2. 
Ivansic, D., Besteher, B., Gantner, J., Guntinas-Lichius, O., Pantev, C., Nenadic, I., et al., 2019. Psychometric assessment of mental health in tinnitus patients, depressive and healthy controls. Psychiatry Res. 281, 112582. https://doi.org/10.1016/j.psychres.2019.112582.

Jalessi, M., Farhadi, M., Asghari, A., Kamrava, S.K., Amintehran, E., Ghalehbaghi, S., et al., 2013. Tinnitus: an epidemiologic study in Iranian population. Acta Med. Iran. 51, 886-891.

Kim, H.-J., Lee, H.-J., An, S.-Y., Sim, S., Park, B., Kim, S.W., Lee, J.S., Hong, S.K., Choi, H.G., 2015. Analysis of the prevalence and associated risk factors of tinnitus in adults. PLoS One 10, e0127578. https://doi.org/10.1371/journal.pone.0127578.

Kostev, K., Alymova, S., Kössl, M., Jacob, L., 2019. Risk factors for tinnitus in 37,692 patients followed in general practices in Germany. Otol. Neurotol. 40, 436-440. https://doi.org/ 10.1097/MAO.0000000000002161.

Kotov, R., Krueger, R.F., Watson, D., Achenbach, T.M., Althoff, R.R., Bagby, R.M., Brown, T.A., Carpenter, W.T., Caspi, A., Clark, L.A., Eaton, N.R., Forbes, M.K., Forbush, K.T., Goldberg, D., Hasin, D., Hyman, S.E., Ivanova, M.Y., Lynam, D.R., Markon, K., et al., 2017. The hierarchical taxonomy of psychopathology (HiTOP): a dimensional alternative to traditional nosologies. J. Abnorm. Psychol. 126, 454-477. https://doi.org/10.1037/abn0000258.

Kreuzer, P.M., Landgrebe, M., Vielsmeier, V., Kleinjung, T., De Ridder, D., Langguth, B., 2014. Trauma-associated tinnitus. J. Head Trauma Rehabil. 29, 432-442. https://doi. org/10.1097/HTR.0b013e31829d3129.

Kuttila, S., Kuttila, M., Bell, Y.L., Alanen, P., Suonpää, J., 2005. Recurrent tinnitus and associated ear symptoms in adults. Int. J. Audiol. 44, 164-170. https://doi.org/ 10.1080/14992020500057608.

Lahey, B.B., Krueger, R.F., Rathouz, P.J., Waldman, I.D., Zald, D.H., 2017. A hierarchical causal taxonomy of psychopathology across the life span. Psychol. Bull. 143, 142-186. https://doi.org/10.1037/bul0000069.

Langguth, B., Landgrebe, M., Kleinjung, T., Sand, G.P., Hajak, G., 2011. Tinnitus and depression. World J. Biol. Psychiatry 12, 489-500. https://doi.org/10.3109/15622975.2011. 575178 .

Langguth, B., Hund, V., Busch, V., Jürgens, T.P., Lainez, J.-M., Landgrebe, M., Schecklmann, M., 2015. Tinnitus and headache. Biomed. Res. Int. 2015, 1-7. https:// doi.org/10.1155/2015/797416.

Lee, S.-Y., Kim, J.-H., Hong, S.-H., Lee, D.-S., 2004. Roles of cognitive characteristics in tinnitus patients. J. Korean Med. Sci. 19, 864. https://doi.org/10.3346/jkms.2004.19.6.864.

LifeGene, 2017. Description of the LifeGene Resource. viewed 27 March 2020, https:// lifegene.se/wp-content/uploads/1LifeGeneresource20170203version24.pdf.

Lin, C.-E., Chen, L.-F., Chou, P.-H., Chung, C.-H., 2018. Increased prevalence and risk of anxiety disorders in adults with tinnitus: a population-based study in Taiwan. Gen. Hosp. Psychiatry 50, 131-136. https://doi.org/10.1016/j.genhosppsych.2017.11.006.

Lugo, A., Trpchevska, N., Liu, X., Biswas, R., Magnusson, C., Gallus, S., Cederroth, C.R., 2019. Sex-specific association of tinnitus with suicide attempts. JAMA Otolaryngol. Neck Surg. 145, 685. https://doi.org/10.1001/jamaoto.2019.0566.

Lugo, A., Edvall, N.K., Lazar, A., Mehraei, G., Lopez-Escamez, J.-A., Bulla, J., et al., 2020. Relationship between headaches and tinnitus in a Swedish study. Sci. Rep. 10, 8494. https://doi.org/10.1038/s41598-020-65395-1. 
Mackinnon, D.P., Dwyer, J.H., 1993. Estimating mediated effects in prevention studies. Eval. Rev. 17, 144-158. https://doi.org/10.1177/0193841X9301700202.

Mahafzah, M.T., Mahafza, T., Omari, H., Al Hawari, H.H., 2018. Investigating the possible audiological effects of hypothyroidism. J. Phon. Audiol. 4. https://doi.org/10.4172/ 2471-9455.1000137.

Malakouti, S., Mahmoudian, M., Alifattahi, N., Salehi, M., 2011. Comorbidity of chronic tinnitus and mental disorders. Int. Tinnitus J. 16, 118-122.

Malik, V., Shukla, G.K., Bhatia, N., 2002. Hearing profile in hypothyroidism. Indian J. Otolaryngol. Head Neck Surg. 54, 285-290. https://doi.org/10.1007/BF02993744.

Martines, F., Sireci, F., Cannizzaro, E., Costanzo, R., Martines, E., Mucia, M., Plescia, F., Salvago, P., 2015. Clinical observations and risk factors for tinnitus in a Sicilian cohort. Eur. Arch. Otorhinolaryngol. 272, 2719-2729. https://doi.org/10.1007/s00405-014-3275-0.

Martinez-Devesa, P., Perera, R., Theodoulou, M., Waddell, A., 2010. Cognitive behavioural therapy for tinnitus. Cochrane Database Syst. Rev. (9), Article No. CD005233. https:// doi.org/10.1002/14651858.CD005233.pub3.

Mathias, K.d.V., Mezzasalma, M.A., Nardi, A.E., 2011. Prevalência de transtorno de pânico em pacientes com zumbidos [the prevalence of panic disorder in patients with tinnitus]. Arch. Clin. Psychiatry 38, 139-142. https://doi.org/10.1590/S0101-60832011000400005.

McCormack, A., Edmondson-Jones, M., Somerset, S., Hall, D., 2016. A systematic review of the reporting of tinnitus prevalence and severity. Hear. Res. 337, 70-79. https://doi.org/ 10.1016/j.heares.2016.05.009.

Menendez, M.E., Baker, D.K., Oladeji, L.O., Fryberger, C.T., McGwin, G., Ponce, B.A., 2015. Psychological distress is associated with greater perceived disability and pain in patients presenting to a shoulder clinic. J. Bone Joint Surg. Am. 97, 1999-2003. https://doi.org/ 10.2106/JBJS.O.00387.

Michikawa, T., Nishiwaki, Y., Kikuchi, Y., Saito, H., Mizutari, K., Okamoto, M., Takebayashi, T., 2010. Prevalence and factors associated with tinnitus: a communitybased study of Japanese elders. J. Epidemiol. 20, 271-276. https://doi.org/10.2188/jea. JE20090121.

Nees, F., Becker, S., 2018. Psychological processes in chronic pain: influences of reward and fear learning as key mechanisms-behavioral evidence, neural circuits, and maladaptive changes. Neuroscience 387, 72-84. https://doi.org/10.1016/j.neuroscience. 2017.08.051.

Nondahl, D.M., Cruickshanks, K.J., Wiley, T.L., Klein, R., Klein, B.E.K., Tweed, T.S., 2002. Prevalence and 5-year incidence of tinnitus among older adults: the epidemiology of hearing loss study. J. Am. Acad. Audiol. 13, 323-331.

Nondahl, D.M., Cruickshanks, K.J., Huang, G.-H., Klein, B.E.K., Klein, R., Javier Nieto, F., Tweed, T.S., 2011. Tinnitus and its risk factors in the beaver dam offspring study. Int. J. Audiol. 50, 313-320. https://doi.org/10.3109/14992027.2010.551220.

Park, K.H., Lee, S.H., Koo, J.-W., Park, H.Y., Lee, K.Y., Choi, Y.S., Oh, K.W., Lee, A., Yang, J.-E., Woo, S.-Y., Kim, S.W., Cho, Y.-S., 2014. Prevalence and associated factors of tinnitus: data from the Korean National Health and Nutrition Examination Survey 2009-2011. J. Epidemiol. 24, 417-426. https://doi.org/10.2188/jea.JE20140024.

Pattyn, T., Van Den Eede, F., Vanneste, S., Cassiers, L., Veltman, D.J., Van De Heyning, P., et al., 2016. Tinnitus and anxiety disorders: a review. Hear. Res. 333, 255-265. https://doi. org/10.1016/j.heares.2015.08.014. 
Pattyn, T., Vanneste, S., De Ridder, D., Van Rompaey, V., Veltman, D.J., Van de Heyning, P., et al., 2018. Differential electrophysiological correlates of panic disorder in non-pulsatile tinnitus. J. Psychosom. Res. 109, 57-62. https://doi.org/10.1016/j.jpsychores.2018.03.168.

Peterson, U., Demerouti, E., Bergström, G., Samuelsson, M., Åsberg, M., Nygren, A., 2008. Burnout and physical and mental health among Swedish healthcare workers. J. Adv. Nurs. 62, 84-95. https://doi.org/10.1111/j.1365-2648.2007.04580.x.

Pinto, P.C.L., Marcelos, C.M., Mezzasalma, M.A., Osterne, F.J.V., de Melo Tavares de Lima, M.A., Nardi, A.E., 2014. Tinnitus and its association with psychiatric disorders: systematic review. J. Laryngol. Otol. 128, 660-664. https://doi.org/10.1017/S0022215114001030.

Probst, T., Pryss, R., Langguth, B., Schlee, W., 2016. Emotional states as mediators between tinnitus loudness and tinnitus distress in daily life: results from the "TrackYourTinnitus" application. Sci. Rep. 6, 1-8, Article No. 20382. https://doi.org/10.1038/srep20382.

Ramage-Morin, P.L., Banks, R., Pineault, D., Atrach, M., 2019. Tinnitus in Canada. Health Rep. 30, 3-11. https://doi.org/10.25318/82-003-x201900300001-eng.

Rauschecker, J.P., May, E.S., Maudoux, A., Ploner, M., 2015. Frontostriatal gating of tinnitus and chronic pain. Trends Cogn. Sci. 19, 567-578. https://doi.org/10.1016/j.tics. 2015.08.002.

Ren, Y.-F., Isberg, A., 1995. Tinnitus in patients with temporomandibular joint internal derangement. Cranio 13, 75-80. https://doi.org/10.1080/08869634.1995.11678048.

Rhee, J., Lee, D., Suh, M.W., Lee, J.H., Hong, Y.-C., Oh, S.H., et al., 2020. Prevalence, associated factors, and comorbidities of tinnitus in adolescents. PLoS One 15, e0236723. https://doi.org/10.1371/journal.pone.0236723.

Rodriguez-Casero, M.V., Mandelstam, S., Kornberg, A.J., Berkowitz, R.G., 2005. Acute tinnitus and hearing loss as the initial symptom of multiple sclerosis in a child. Int. J. Pediatr. Otorhinolaryngol. 69, 123-126. https://doi.org/10.1016/j.ijporl.2004.08.006.

Romero Sánchez, I., Pérez Garrigues, H., Rodríguez Rivera, V., 2010. Clinical characteristics of tinnitus in Ménière's disease. Acta Otorrinolaringol. Esp. 61, 327-331. https://doi.org/ 10.1016/S2173-5735(10)70060-0.

Sahin, C., Aras, H.İ., Yilmaz, M.S., 2016. Somatoform disorders in patients with chronic subjective tinnitus. Eur. Arch. Otorhinolaryngol. 273, 3603-3607. https://doi.org/ 10.1007/s00405-016-3968-7.

Salazar, J.W., Meisel, K., Smith, E.R., Quiggle, A., McCoy, D.B., Amans, M.R., 2019. Depression in patients with tinnitus: a systematic review. Otolaryngol. Head Neck Surg. 161, 28-35. https://doi.org/10.1177/0194599819835178.

Seligman, F., Nemeroff, C.B., 2015. The interface of depression and cardiovascular disease: therapeutic implications. Ann. N. Y. Acad. Sci. 1345, 25-35. https://doi.org/10.1111/ nyas. 12738.

Seo, J.H., Kang, J.M., Hwang, S.H., Han, K.D., Joo, Y.H., 2016. Relationship between tinnitus and suicidal behaviour in Korean men and women: a cross-sectional study. Clin. Otolaryngol. 41, 222-227. https://doi.org/10.1111/coa.12500.

Shargorodsky, J., Curhan, G.C., Farwell, W.R., 2010. Prevalence and characteristics of tinnitus among US adults. Am. J. Med. 123, 711-718. https://doi.org/10.1016/j.amjmed. 2010.02.015.

Sharlin, D.S., Ng, L., Verrey, F., Visser, T.J., Liu, Y., Olszewski, R.T., Hoa, M., Heuer, H., Forrest, D., 2018. Deafness and loss of cochlear hair cells in the absence of thyroid hormone transporters Slc16a2 (Mct8) and Slc16a10 (Mct10). Sci. Rep. 8, 4403. https:// doi.org/10.1038/s41598-018-22553-w. 
Shih, C.-P., Lin, H.-C., Chung, C.-H., Hsiao, P.-J., Wang, C.-H., Lee, J.-C., et al., 2017. Increased risk of tinnitus in patients with chronic kidney disease: a nationwide, population-based cohort study. PLoS One 12, e0183192. https://doi.org/10.1371/journal. pone.0183192.

Shore, S.E., Roberts, L.E., Langguth, B., 2016. Maladaptive plasticity in tinnitus-triggers, mechanisms and treatment. Nat. Rev. Neurol. 12, 150-160. https://doi.org/10.1038/ nrneurol.2016.12.

Siivola, S.M., Levoska, S., Latvala, K., Hoskio, E., Vanharanta, H., Keinänen-Kiukaanniemi, S., 2004. Predictive factors for neck and shoulder pain: a longitudinal study in young adults. Spine 29, 1662-1669. https://doi.org/10.1097/01.BRS.0000133644.29390.43.

Sindhusake, D., Golding, M., Newall, P., Rubin, G., Jakobsen, K., Mitchell, P., 2003. Risk factors for tinnitus in a population of older adults: the Blue Mountains hearing study. Ear Hear. 24, 501-507. https://doi.org/10.1097/01.AUD.0000100204.08771.3D.

Singh, R., Aftab, M., Jain, S., Kumar, D., 2019. Audiological evaluation in hypothyroid patients and effect of thyroxine replacement therapy. Indian J. Otolaryngol. Head Neck Surg. 71, 548-552. https://doi.org/10.1007/s12070-018-1395-3.

Skov, T., Borg, V., Orhede, E., 1996. Psychosocial and physical risk factors for musculoskeletal disorders of the neck, shoulders, and lower back in salespeople. Occup. Environ. Med. $53,351-356$.

Spankovich, C., Gonzalez, V.B., Su, D., Bishop, C.E., 2018. Self reported hearing difficulty, tinnitus, and normal audiometric thresholds, the National Health and Nutrition Examination Survey 1999-2002. Hear. Res. 358, 30-36. https://doi.org/10.1016/j.heares.2017.12.001.

Stobik, C., Weber, R.K., Münte, T.F., Walter, M., Frommer, J., 2005. Evidence of psychosomatic influences in compensated and decompensated tinnitus. Int. J. Audiol. 44, 370-378. https://doi.org/10.1080/14992020500147557.

Stohler, N.A., Reinau, D., Jick, S.S., Bodmer, D., Meier, C.R., 2019. A study on the epidemiology of tinnitus in the United Kingdom. Clin. Epidemiol. 11, 855-871. https://doi.org/ 10.2147/CLEP.S213136.

Stouffer, J.L., Tyler, R.S., 1990. Characterization of tinnitus by tinnitus patients. J. Speech Hear. Disord. 55, 439-453. https://doi.org/10.1044/jshd.5503.439.

Turner, J., Kelly, B., 2000. Emotional dimensions of chronic disease. West. J. Med. 172, 124-128. https://doi.org/10.1136/ewjm.172.2.124.

Tyler, R.S., Baker, L.J., 1983. Difficulties experienced by tinnitus sufferers. J. Speech Hear. Disord. 48, 150-154. https://doi.org/10.1044/jshd.4802.150.

Uziel, A., Legrand, C., Rabie, A., 1985. Corrective effects of thyroxine on cochlear abnormalities induced by congenital hypothyroidism in the rat. I. Morphological study. Dev. Brain Res. 19, 111-122. https://doi.org/10.1016/0165-3806(85)90236-6.

van de Leemput, I.A., Wichers, M., Cramer, A.O.J., Borsboom, D., Tuerlinckx, F., Kuppens, P., et al., 2014. Critical slowing down as early warning for the onset and termination of depression. Proc. Natl. Acad. Sci. 111, 87-92. https://doi.org/10.1073/pnas. 1312114110.

Waylonis, G.W., Heck, W., 1992. Fibromyalgia syndrome: new associations. Am. J. Phys. Med. Rehabil. 71, 343-348. https://doi.org/10.1097/00002060-199212000-00006.

Weise, C., Hesser, H., Andersson, G., Nyenhuis, N., Zastrutzki, S., Kröner-Herwig, B., Jäger, B., 2013. The role of catastrophizing in recent onset tinnitus: its nature and association with tinnitus distress and medical utilization. Int. J. Audiol. 52, 177-188. https://doi. org/10.3109/14992027.2012.752111. 


\section{CHAPTER 3 Comorbidities in bothersome tinnitus}

Yang, P., Ma, W., Zheng, Y., Yang, H., Lin, H., 2015. A systematic review and meta-analysis on the association between hypertension and tinnitus. Int. J. Hypertens. 2015, 1-7. https:// doi.org/10.1155/2015/583493.

Yoshida, T., Stephens, D., Kentala, E., Levo, H., Auramo, Y., Poe, D., Pyykkö, I., 2011. Tinnitus complaint behaviour in long-standing Menière's disorder: its association with the other cardinal symptoms. Clin. Otolaryngol. 36, 461-467. https://doi.org/10.1111/ j.1749-4486.2011.02381.x.

Ziai, K., Moshtaghi, O., Mahboubi, H., Djalilian, H.R., 2017. Tinnitus patients suffering from anxiety and depression: a review. Int. Tinnitus J. 21, https://doi.org/10.5935/09465448.20170013. 